Original Article

\title{
EVOLUTION OF NANOTECH ASSISTED PCR DIAGNOSIS OF MYCOBACTERIUM TUBERCULOSIS AND ITS ASSESSMENT WITH CONVENTIONAL METHODS
}

\author{
DEEPAK V. SAWANT ${ }^{a, b}$, M. M. DESAI ${ }^{b}$, R. S. PATIL ${ }^{b}$, S. H. PAWAR ${ }^{a, c^{*}}$ \\ aCentre for Interdisciplinary Research, D. Y. Patil University, Kolhapur, 416006, M. S, India, 'b. Y. Patil, Medical College, Hospital and \\ Research Institute, Kolhapur, 416006, M. S, India, cCentre for Research and Technology Development, Sinhagad Institutes Solapur, \\ 413255, M. S, India \\ Email: shpawar1946@gmail.com
}

Received: 02 Dec 2017 Revised and Accepted: 01 Feb 2018

\begin{abstract}
Objective: This study was focused on assessment and performance of conventional and nanotech assisted methods for detection of Mycobacterium tuberculosis. Tuberculosis (TB) still leftovers one of the top ten causes of death worldwide, thus this study has undertaken the use of MNP for early detection of TB.

Methods: A cross-sectional studies were conducted on clinical and radiological suspected TB patients in the department of microbiology at D. Y. Patil hospital Kolhapur. All samples received in the month of August 2016 to January 2017. Total One hundred twenty-sputum samples were
\end{abstract} processed for diagnosis of TB by ZN stain, culture on L. J. Medium and real-time PCR tests.

Results: In our present study, 60.83\% (73) patient male and $39.17 \%$ (47) were female patient, showing a borderline male prevalence found in our study. Eighteen percent patients were found to be in the age group (21-30 y) are mostly affected for pulmonary tuberculosis. A significant difference was seen in the percentage of different DNA extraction methods, the fig. being conventional chloroform-phenol $66.66 \%$, the commercial kit $80 \%$, magnetic bead $86.66 \%$ and MNPs method $99.66 \%$ found to be significant $\left(\mathrm{P}<0.0001^{* *}\right)$.

Conclusion: In the present study the MNP-DNA extraction techniques with NALC followed by IS6110 target amplification were found superior for diagnosis of TB. The MNP assisted extraction method showed better results in terms of quantification and sensitivity of TB PCR diagnosis, evolving nanotech assisted innovative method.

Keywords: PCR-polymer chain reaction, MNP-magnetic nanoparticle, DNA-deoxyribonucleic acid NALC-N-acetyl-L-Cysteine

(c) 2018 The Authors. Published by Innovare Academic Sciences Pvt Ltd. This is an open access article under the CC BY license (http://creativecommons.org/licenses/by/4.0/) DOI: http://dx.doi.org/10.22159/ijpps.2018v10i3.24085

\section{INTRODUCTION}

Tuberculosis (TB) has existed for millennia and remains a major global health problem. It causes ill health in millions of people each year. India has a high burden of TB cases, In India, 15 million suffers from TB, of which over 3 million are highly infections open cases. Half of a million people die from the disease every year, every two minutes one TB patient death. Tuberculosis is an ancient disease, it is estimated that a one-third of the world's population [1]. An estimated 22 million lives saved through the use of DOTS and the stop TB strategy recommended by World health organization (WHO). The WHO's "End TB" strategy aims to reduce TB deaths by $95 \%$, reduce new cases by $90 \%$ between 2015 and 2035 and ensure that no family is burdened with catastrophic expenses due to TB [2]. Most of the conventional methods used for detecting Mycobacterium tuberculosis bacilli (MTB) depends on microscopic sputum smear examination and culture techniques. Which involve tedious process, requires skilled persons to handle the test, and take more time to produce the result varying from several days to months. Further, these conventional methods are less sensitive that it can detect only half of the active MTB. The conventional method of detection of MTB, though simple, still depends on AFB staining method and requires $5000-10000$ bacilli/ml for detection of MTB. In addition, phenotypic identification such as culture and biochemical study, include the velocity of growth; colony morphology; pigment production, urease test, niacin test; nitrate reduction test; catalase activity; pyrazinamide test: growth in the presence of pNitrobenzoic acid. In this background, in recent year's one new approach for rapid, safe and reproducible identification of MTB infection is real-time polymer chain reaction (RT-PCR).

The success of final amplification and detection of nucleic acid amplification test (NAAT) depends on successful extraction from a pulmonary sputum sample. Real-time PCR is an identical sensitive technique for detection of communicable disease, but the sensitivity of the assessment is mostly dependent on the productivity of the DNA extraction method [3]. The demand for PCR diagnosis in medical microbiology has highlighted the need for an efficient method of nucleic acid extraction. Presently magnetic beads are used for mycobacterial DNA extraction, these are polycrystalline in nature and macroscopic.

However recently the nanoparticles with super-paramagnetic properties such as $\mathrm{Fe}_{3} \mathrm{O}_{4}, \mathrm{Co} 0.5 \mathrm{Zn} 0.5 \mathrm{Fe}_{2} \mathrm{O}_{4}$ (CZF) [4], synthesized cobalt ferrite $\left(\mathrm{CoFe}_{2} \mathrm{O}_{4}\right)$ [5], $\mathrm{Ni0} .5 \mathrm{Zn} 0.5 \mathrm{Fe}_{2} \mathrm{O}_{4}$ [6], $\mathrm{La} 0.7 \mathrm{Sr} 0.3 \mathrm{MnO}_{3}$ (LSMO) [7], MnxMg1- $\mathrm{xFe}_{2} \mathrm{O}_{4}$ [8], $\mathrm{Fe}_{3} \mathrm{O}_{4}$ and $\mathrm{CS}-\mathrm{Fe}_{3} \mathrm{O}_{4}$ [9], $\mathrm{La} 0.7 \mathrm{Sr} 0.3 \mathrm{MnO}_{3}$ (LASMO) [10]. These materials can be used for extraction of mycobacterial DNA. In the present study, $\mathrm{Fe}_{3} \mathrm{O}_{4}$ nanoparticle has been synthesized and used for mycobacterial DNA detection with higher efficiencies than that of the magnetic beads and tested for clinical samples [11]. These results are found superior than conventional methods. The magnetic nanoparticle (MNP) assisted DNA extraction protocol showed better results in terms of quantification and sensitivity of PCR diagnosis of Mycobacterium tuberculosis, evolving nanotech assisted innovative method [12].

\section{MATERIALS AND METHODS}

\section{Experimental protocol}

Total one hundred and twenty clinically suspected TB patients were selected for cross-sectional study, in microbiology laboratory of D. Y. Patil Hospital Kolhapur from August 2016 to January 2017.

Master chart and graphs are prepared by using MS Excel 2007. Data analysis is done in graphpad instat software. The Means of all quantitative variables which follows a normal distribution are 
compared by unpaired t-test and which do not follow normal distribution are compared by "Wilcoxions signed rank test". Probability $(\mathrm{P}<0.05)$ is considered statistically significant.

\section{Selection of patient}

\section{Inclusion}

Criteria include clinically diagnosed and radiological documented new cases of pulmonary Mycobacterium tuberculosis of any gender and age group or untreated MTB cases, patients with antituberculosis drug therapy in past 6 mo.

\section{Exclusion}

Criteria include patients with anti TB therapy or its constituent's drugs in the past 3 mo.

The control group was also studied from the patient who had a diagnosis other than pulmonary tuberculosis.

\section{Sample pre-treatment}

All samples were used for this study are confirmed by the conventional microscopic observation by using acid-fast staining using ZN (Ziehl-Neelsen) stain. The pulmonary sputum samples are obtained from the clinical and radiological evidence of tuberculosis and these samples are selected for DNA-extraction [13]. All specimens were treated with $0.5 \% \mathrm{~N}$-acetyl-L-Cysteine (NALC)/2\% $\mathrm{NaOH}$ method for digestion and decontaminated and concentrated by centrifuging at $3000 \mathrm{rpm}$ for $15 \mathrm{~min}$. The supernatant is decanted and transferred the sediment in $2 \mathrm{ml}$ of phosphate buffer $\mathrm{pH} 6.8$. The sediment is used for ZN staining and DNA extraction. Acid-fast bacilli (AFB) smear microscopy and culture shown in (fig. 1).

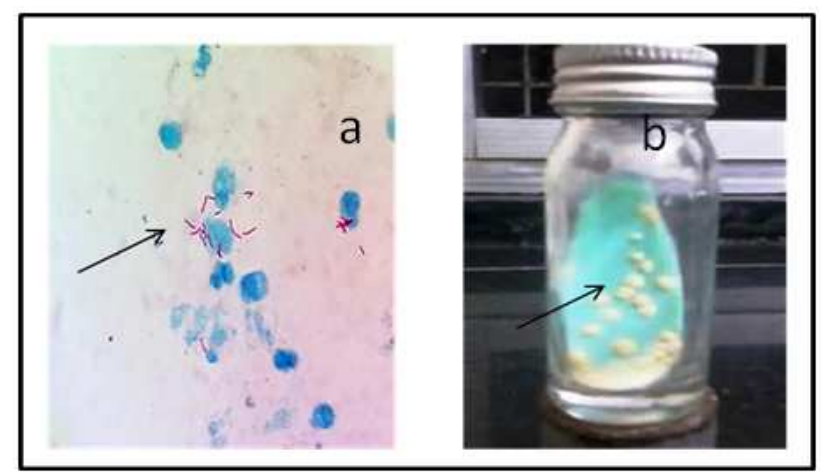

Fig. 1a: Acid fast bacilli (Z-N stain). 1b. Mycobacterium tuberculosis grown on $\mathrm{L} \mathrm{J}$. Medium

\section{DNA extraction}

Conventional, commercial and MNP methods were employed for the extraction of DNA samples. DNA was extracted by the conventional chloroform-phenol method and commercially available QI Amp DNA kit (QIAGEN) with one initial additional step. The pre-treated samples were kept at $80^{\circ} \mathrm{C}$ for $10 \mathrm{~min}$ for inactivation of mycobacteria. The material was then further processed as per the manufacturer guidelines. For magnetic DNA extraction method after cell lysis, $100 \mu \mathrm{l}$ magnetic nanoparticle is added into the micro centrifuge tube, MNPs are immobilized by an external magnet, by using elution buffer and DNA was separated and kept in $-20^{\circ} \mathrm{C}$ [13].

\section{Real-time PCR conditions}

Isolated DNA samples are processed for amplification by real-time PCR (Rotor Gene 2000/3000/6000-Corbett Research, Australia) for in vitro diagnostic use. Total $25 \mu \mathrm{l}$ reaction volume of master mix it contains $12 \mu \mathrm{l}(\mathrm{R} 1)$ super mix, magnesium solution, MTB complex $2.5 \mu \mathrm{l}(\mathrm{R} 2)$ and internal control IC-1 (R3) RG $0.5 \mu \mathrm{l}$ and $10 \mu \mathrm{l}$ extracted DNA samples. The PCR grade water used as a negative control. Cycling conditions were 1 cycle initial activation at $95^{\circ} \mathrm{C}$ for
10 min, a number of cycles 45 cycles, denaturation at $95{ }^{\circ} \mathrm{C}$ for 15 seconds, annealing at $60^{\circ} \mathrm{C}$ for 20 seconds and an extension step at $72{ }^{\circ} \mathrm{C}$ for 15 seconds.

\section{Ethical considerations}

Ethics approval to conduct this study was granted by the Institutional Ethical Committee of D. Y. Patil University, Kolhapur, 416006, Maharashtra, India (2016/44/PA-Ph. D).

\section{RESULTS}

\section{Statistical analysis of DNA extraction}

Statistical significance of four different methods for DNA extracting methods was analyzed. The efficiency of each DNA extracting protocol was compared using the data analysis package included within graph pad instat software the mean of quantitative variables which follow a normal distribution are compared by unpaired t-test (table 1 to 3). Mean of quantitative variables which do not follow normal distribution are compared by using the Wilcoxon signed rank test $\left(\mathrm{P}<0.0001^{* *}\right)$ which shown in table 4 to 6 . The probability is considered statistically significant*. The mean crossing threshold (Ct) values for four extracted methods are positive for real-time PCR [14]. The highest $\mathrm{Ct}$ values obtained were 27.5 for phenolchloroform, 23.8 for commercial kit, 21.3 for MNP and 24.8 for magnetic bead. These results indicated, all samples are positive for MTB but the Ct value shows 21.3 for MNPs is lower as compared to commercial kit and magnetic beads. For phenol-chloroform, organic method Ct value 27.5 is high as compared to other extracted methods as it contains PCR inhibitor. MNPs mediated DNA extraction technique proves to be rapid, inexpensive and robust as compared to commercial kit.

\section{Statistical analysis of clinical samples}

In the present study, out of 120 , male 73 patients and 47 were female patients showing a marginal female preponderance. In this study, 15 patients were in the age group $11-20$ y highest $35 \mathrm{~TB}$ patients are seen in 21-30 age group. Ziehl Neelsen staining was performed on smears of all sputum samples and distributed in grade wise, which shows grade I-8 patients, grade II, 2 patients, grade III- 2 patients and grade IV-O patients in the age group 11-20, were shown in fig. 2.

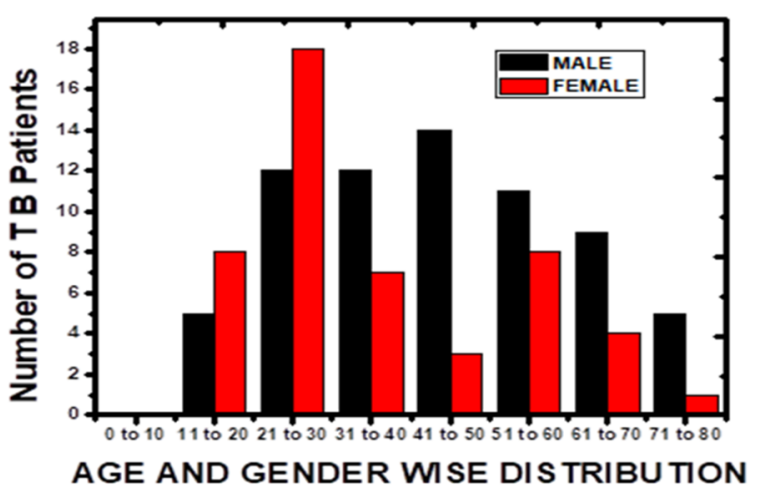

Fig. 2: Distribution of tuberculosis cases

Comparison of DNA extraction methods and the efficiencies of DNA extraction protocols were compared with the yield of DNA of the different extraction methods. These results are listed in table 1 to 6 . It was found that MNP based cell separation was more efficient than the conventional phenol-chloroform method and commercial methods in $\left(\mathrm{P}<0.0001^{* *}\right)$ probability is considered statistically significant. To summarize the results with different extraction methods in combination with DNA purification from MNp cell separation, the conventional chloroform-phenol method consistently produce the highest $\mathrm{Ct}$ value in contrast to manufactures protocol. MNP method gives lowest Ct value and gives highest pure DNA yield. 
Evaluation of the newly developed extraction protocol and real time PCR

For evaluation of conventional and nanotech assisted methods, we select 120 smear positive samples and submitted for DNA extraction by four different methods. All positive samples were confirmed by real-time PCR. According to this study, the MNP extraction method has great impact. It was observed that by MNP mediated mycobacterial DNA extraction method $96.66 \%$ of the positive cases are detected by conventional chloroform-phenol method $66.66 \%$ of the cases are detected, by commercial kit method $80 \%$ of the cases are detected and mag. bead-kit method $86.66 \%$, were shown in fig. 3 . Therefore, it is observed that by MNP method is more superior to that of the conventional and commercial method.

\section{Purity and yield of DNA $\left(A_{260} / A_{280}\right)$}

Data analysis is performed by graphpad instat software. Mean of quantitative variables which follow a normal distribution are compared by unpaired t-test. Mean of quantitative variables which do not follow normal distribution are compared by using the
Wilcoxon signed rank test $\mathrm{P}<0.0001^{* *}$ probability is considered statistically significant.*

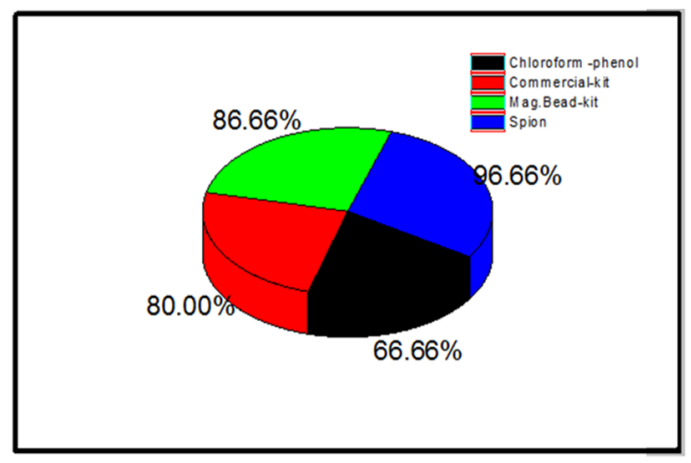

Fig. 3: Distribution of samples in percentage

Table 1: The yield of MNPs-DNA method Vs chloroform-phenol by unpaired t-test

\begin{tabular}{lllll}
\hline & MNPs-method $(\overline{\mathbf{X}} \pm$ SD $)$ & Chl.-phenol $(\overline{\mathbf{X}} \pm$ SD) & P-value & Statistical test used \\
\hline Yield of DNA & $1.742 \pm 0.043$ & $2.224 \pm 0.097$ & $\mathrm{P}<0.0001^{* *}$ & Unpaired t-test \\
N & 30 & 30 & & \\
SEM & 0.0078 & 0.0178 & & \\
C. I. & $1.726-1.758$ & $2.188-2.261$ & & \\
\hline
\end{tabular}

$\overline{\mathrm{X}} \pm$ SD denotes the values in mean \pm STD deviation values of yield DNA are expressed in: $\bar{X} \pm S D,(n=30), p<0.05$ is considered statistically significant, *shows statistically significance.

The mean ratio of MNPs and chloroform-phenol method are compared by unpaired t-test which is statistically significant. Ratio by MNPs method is significantly more than chloroform-phenol method $\left(\mathrm{P}<0.0001^{* *}\right)$

Table 2: The yield of MNPs-DNA method Vs commercial kit method unpaired t-test

\begin{tabular}{lllll}
\hline & MNPs-method $(\overline{\mathbf{X}} \pm$ SD) & Comm. Kit. $(\overline{\mathbf{X}} \pm$ SD) & P-value & Statistical test used \\
\hline Yield of DNA & $1.742 \pm 0.043$ & $1.43 \pm 0.1348$ & $\mathrm{P}<0.0001^{* *}$ & Unpaired t-test \\
$\mathrm{N}$ & 30 & 30 & & \\
SEM & 0.0078 & 0.0246 & & \\
C. I. & $1.726-1.758$ & $1.382-1.483$ & & \\
\hline
\end{tabular}

$\bar{X} \pm$ SD denotes the values in mean \pm STD deviation values of yield DNA are expressed in: $\bar{X} \pm S D,(n=30), p<0.05$ is considered statistically significant, *shows statistically significance.

The mean ratio of MNPs and chloroform-phenol method are compared by unpaired t-test which is statistically significant. Ratio by MNPs method is significantly more than chloroform-phenol method $\left(\mathrm{P}<0.0001^{* *}\right)$.

Table 3: The yield of MNPs-DNA method Vs magnetic bead unpaired t-test

\begin{tabular}{lllll}
\hline & MNPs-method $(\overline{\mathbf{X}} \pm$ SD $)$ & Mag. bead $(\overline{\mathbf{X}} \pm$ SD $)$ & P-value & Statistical test used \\
\hline Yield of DNA & $1.742 \pm 0.043$ & $1.713 \pm 0.14$ & $\mathrm{P}<0.0001^{* *}$ & Unpaired t-test \\
$\mathrm{N}$ & 30 & 30 & & \\
SEM & 0.0078 & 0.02668 & & \\
C. I. & $1.726-1.758$ & $1.65-1.76$ & & \\
\hline
\end{tabular}

$\overline{\mathrm{X}} \pm$ SD denotes the values in mean \pm STD deviation values of yield DNA are expressed in: $\bar{X} \pm S D,(n=30), p<0.05$ is considered statistically significant, *shows statistically significance.

The Mean ratio of MNPs and magnetic bead method are compared by unpaired t-test which is statistically significant. The ratio by MNPs method is significantly more than magnetic bead method $\left(\mathrm{P}<0.0001^{* *}\right)$.

Table 4: The yield of MNPs-DNA method Vs Chl.-phenol method by wilcoxon signed rank test

\begin{tabular}{lllll}
\hline & MNPs-method $(\overline{\mathbf{X}} \pm$ SD) & Chl. phenol $(\overline{\mathbf{X}} \pm$ SD) & P-value & Statistical test used \\
\hline Yield of DNA & $845.633 \pm 101.02$ & $75.34 \pm 8.895$ & $\mathrm{P}<0.0001^{* *}$ & Wilcoxon S. Rank \\
N & 30 & 30 & & \\
SEM & 18.443 & 1.624 & & \\
C. I. & $807.92-883.35$ & $72.026-78.668$ & & \\
\hline
\end{tabular}

$\overline{\mathrm{X}} \pm \mathrm{SD}$ denotes the values in mean $\pm S T D$ deviation values of yield DNA are expressed in: $\overline{\mathrm{X}} \pm \mathrm{SD},(\mathrm{n}=30), \mathrm{p}<0.05$ is considered statistically significant, *shows statistically significance.

The mean ratio of MNPs and chloroform-phenol method are compared by Wilcoxon signed rank test which is statistically significant. Ratio by MNPs method is significantly more than chloroform-phenol method $\left(\mathrm{P}<0.0001^{* *}\right)$. 
Table 5: The yield of MNPs-DNA method Vs comm. kit method by wilcoxon signed rank test

\begin{tabular}{llll}
\hline & MNPs-method $(\overline{\mathbf{X}} \pm$ SD) & Com. Kit $(\overline{\mathbf{X}} \pm$ SD) & P-value \\
\hline Yield of DNA & $845.633 \pm 101.02$ & $331.4 \pm 44.487$ & Ptatistical test used \\
N & 30 & $30.0001^{* *}$ & Wilcoxon S. Rank \\
SEM & 18.443 & 8.122 & \\
C. $I$. & $807.92-883.35$ & $314.79-348.01$ & \\
\hline
\end{tabular}

$\overline{\mathrm{X}} \pm \mathrm{SD} \pm \mathrm{SD}$ denotes the values in mean \pm STD deviation values of yield DNA are expressed in: $\overline{\mathbf{X}} \pm \mathrm{SD},(\mathrm{n}=30$ ), $\mathrm{p}<0.05$ is considered statistically significant, *shows statistically significance.

The mean ratio of MNPs and commercial kit method are compared by Wilcoxon signed rank test which is statistically significant. Ratio by MNPs method is significantly more than commercial kit method $\left(\mathrm{P}<0.0001^{* *}\right)$

Table 6: The yield of MNPs DNA method Vs Mag. bead method by wilcoxon signed rank test

\begin{tabular}{llll}
\hline & MNPs-method $(\overline{\mathbf{X}} \pm \mathbf{S D})$ & Mag. bead $(\overline{\mathbf{X}} \pm \mathbf{S D})$ & P-value \\
\hline Yield of DNA & $845.633 \pm 101.02$ & $680.86 \pm 84.92$ & P $<0.0001^{* *}$ \\
N & 30 & 30 & Wilcoxon S. Rank \\
SEM & 18.443 & 8.122 & \\
C. I. & $807.92-883.35$ & $649.16-712.57$ & \\
\hline
\end{tabular}

$\overline{\mathrm{X}} \pm$ SDdenotes the values in mean \pm STD deviation values of yield DNA are expressed in: $\bar{X} \pm S D,(n=30), p<0.05$ is considered statistically significant, * shows statistically significance.

The mean ratio of MNPs and magnetic bead kit method are compared by Wilcoxon signed rank test which is statistically significant. The ratio by MNPs method is significantly more than maganetic bead kit method $\left(\mathrm{P}<0.0001^{* *}\right)$.

\section{DISCUSSION}

PCR diagnosis of Mycobacterium tuberculosis infection is the best molecular technique, it proves specificity, sensitivity and rapid PCR test [15]. In this study, we focus on the evolution of nanotech assisted PCR diagnosis of $M$. tuberculosis and its assessment with the conventional methods for the detection of $M$. tuberculosis. Conventional methods for bacteriological detection of TB are still based on microscopic visualization of AFB in sputum samples, for growing this micro-organism in the culture of L. J. media for later identification [16]. Sputum smear microscopy method is most commonly used in the detection of the pulmonary tuberculosis because it is simple, rapid, and inexpensive despite its low sensitivity. In India, where culture methods, are still used as the gold standard, but this method is time-consuming and delays in diagnosis [16]. It may take one to two months because the organism is slow growing. Mostly culture is performed in the positive smear in the second month of treatment, MDR (multi-drug resistant) TB patient with previous history, immunosuppressed patients [17]. Nanotech base methods have the advantage of being earlier than culture-based methods and reduce the delay for TB detection. Nanotech methods are now more reliable as compared to conventional methods, in this study RT-PCR detected a higher number of confirmed TB cases [18]. Real-time PCR results depend on quality, quantity and pure DNA. In our study, the combination with magnetic nanoparticle with realtime PCR is an effective tool for detection of M. tuberculosis directly from pulmonary sputum sample [19]. The sample distribution according to age and gender-wise, varied greatly as a maximum number of sputum sample as compare to extra pulmonary sample. The more number of AF positive sample and culture positive could be recognized to the significantly more number of sputum samples. Occasionally, problems with false positive real-time PCR results, are reported may be due to variations between laboratories due to technical differences and cross contamination. PCR method is highly sensitive and specific, for low bacilli containing in samples [20]. The disadvantage of PCR is its high cost, molecular lab infrastructure and skilled technologist. At present-day, in India real-time PCR is suitable as a public tool for rapid and early detection of TB [21]. Nanotech assisted PCR with higher efficiencies has been evolved [22-24]. In the present investigations, it is attributed to more significant and innovative properties of nanoparticles than that of magnetic beads.

\section{CONCLUSION}

The success of final amplification and detection of DNA depends on the extraction of good quality DNA free from protein, lipids and RNA.
The extraction protocol using the magnetic nanoparticle showed the best results in terms of quantification and sensitivity of real-time PCR amplification. The MNP-DNA extraction with NALC followed by IS6110 target amplification could be an effective tool for detection of M. tuberculosis from a pulmonary sputum sample. The reported method in the article will definitely stand to be the one of the newer, safer, cheaper, and better alternatives and hold tremendous potential to replace the current techniques.

\section{LIMITATION OF STUDY}

The extraction protocol by using MNP are better than other conventional and commercial kit method we are able to extract highest yield of DNA (845.6ng/ul). The extraction yield of DNA can give more results by using other super paramagnetic properties. Recently, however many more MNPs with core structure have shown higher magnitudes of magnetisms and needs to be tried for such kind of studies.

\section{ACKNOWLEDGEMENT}

The author gratefully to the Wanles Hospital Miraj for providing real-time PCR facilities. The author is also thanks to CRTD Sinhagad Institutes Solapur for encouraging the nanotech research.

\section{AUTHORS CONTRIBUTION}

All authors certify that they have participated satisfactorily in the work to make public responsibility for the content, including involvement in the concept, design, analysis, writing or revision of the manuscript.

\section{CONFLICT OF INTERESTS}

The authors have declared that they have no conflict of interest.

\section{REFERENCES}

1. World Health Organization. Global Tuberculosis Report. Available from: http://www.who.int/tb/publications/ global_ report/enz,2015. [Last accessed on 01 Nov 2017].

2. E Petersen, Ben Marais, Giovanni BM, Peter M, Francine N, Cris V, et al. World TB Day 2017: Advances, Challenges and Opportunities in the "End-TB" Era. Int J Inf Diseases 2017;56:1-5.

3. World Health Organization. Tuberculosis Country Profiles; 2016. Available from: http://www.who.int/tb/country/data/ profiles/en. [Last accessed on 01 Nov 2017].

4. Nikam DS, Jadhav SV, Khot VM, Ningthoujam RS, Chang KH, Mali SS, et al. Colloidal stability of polyethene glycol functionalized Co0.5Zn0.5Fe2O4 nanoparticles: effect of $\mathrm{pH}$, 
sample and salt concentration for hyperthermia application. RSC Advance 2014;14:12662-71.

5. Salunkhe AB, Khot VM, Phadatare MR, Pawar SH. Combustion synthesis of cobalt ferrite nanoparticles Influence of fuel to oxidizer ratio. J Alloys Compounds 2012;514:91-6.

6. Phadatare MR, Meshram JV, Gurav KV, Kim JH, Pawar SH. Enhancement of specific absorption rate by exchange coupling of the core-shell structure of magnetic nanoparticles for magnetic hyperthermia. J Phys D: Appl Phys 2016;49:1-9.

7. Thorat ND, Patil RM, Khot VM, Salunkhe VM, Prasad AI, Barick KC, et al. Highly water-dispersible surface-functionalized LSMO nanoparticles for magnetic fluid hyperthermia application. New J Chem 2013;10:1-14.

8. Khot VM, Salunkhe AB, Phadatare MR, Thorat ND, Pawar SH. Low-temperature synthesis of MnxMg1-xFe204 ( $\mathrm{x}=0-1)$ nanoparticles: cation distribution, structural and magnetic properties. J Phys D: Appl Phys 2013;46:1-8.

9. Shete PB, Patil RM, Thorat ND, Prasad A, Ningthoujam RS, Ghosh SJ, et al. Magnetic chitosan nanocomposite for hyperthermia therapy application: preparation, characterization and in vitro experiments. Appl Surface Sci 2013;161:1-44.

10. Jadhav SV, Lee SH, Nikam DS, Bohara RA, Pawar SH, Yun SY. Studies on enhanced colloidal stability and heating ability of glycine functionalized LSMO nanoparticles for cancer hyperthermia therapy. N J Chem 2017;16:1-11.

11. Pinhata JM, Novella MC, Carmo AM, Silva RR, Ferrazoli L, Sacchi $\mathrm{CT}$, et al. Rapid detection of mycobacterium tuberculosis complex by real-time PCR in sputum samples and its use in the routine diagnosis in a reference laboratory. J F Med Microbiol 2015;64:1040-5.

12. Palomo FS, Rivero MG, Quiles F, Pinto P, Machado AM, Pinatari AC. Comparison of DNA extraction protocols and molecular targets to diagnose tuberculosis meningitis. Tuberculosis research and treatment: 2017:46:1-6.

13. Ssengooba W, Respeito D, Mambuque E, Bianco S, Bulo H, Mandomando I, Jong BC, Cobelens FG, Garcia-Basteiro AL, Do Xpert MTB/RIF Cycle threshold values provide information about patient delays for Tuberculosis Diagnosis, PLOS-ONE, 2016:11:1-9.
14. Almeida IN, Figueredo LJ, Soares VM, Vater MC, Suely Alves, Carvalho WC, et al. Evaluation of the mean cost and activitybased cost in the diagnosis of pulmonary tuberculosis in the laboratory routine of a high complexity hospital in brazil. Front Microbiol 2017;8:1-7.

15. Oberoi NS, Chopra A, Singh G, Varghese N. Concurrent evaluation conventional vs rapid techniques for diagnosis of tuberculosis in a tertiary care centre of Punjab. JERMM 2016;2:6-9.

16. Rakotosamimanna N, Rabodoariveio M, Palomino J, Martin A, Razanamparany VR. Exploring tuberculosis by molecular tests on DNA isolated from smear microscopy slides. Int J Inf Diseases 2017;56:248-52.

17. Eric TY, Zheng LL, Rity Y, Wong K, Chan WC, Au TK, et al. Rapid and simultaneous detection of mycobacterium tuberculosis complex and Beijing/w genotype in sputum by an optimized DNA extraction protocol and a novel multiplex real-time PCR. J Clin Microbiol 2011;56:2509-15.

18. Li yi, Ying Huang, Ting $\mathrm{Wu}$, Jun wu. A magnetic nanoparticlebased method for DNA extraction from the saliva of stoke patients. Neural Regeneration Res 2013;8:3036-46.

19. Pinhata JM, Novella MC, Carmo AM, ferrazoli RF, Sachhi CT, Oliveira RS. Rapid detection of mycobacterium tuberculosis complex by real-time PCR in sputum samples and its use in the routine diagnosis in a reference laboratory. J Med Microbiol 2015;64:1040-5.

20. Chang CC, Chen CC, Chung S Wei, Hui-hsin lu, lian YG, Lin CW. Sensors. 2012;12:8319-37.

21. Palomo FS, Rivero MG, Quiles F, Pinto P, Machado AM, Pignatari AC. Comparison of DNA extraction protocols and molecular targets to diagnose tuberculous meningitis. Tuberc Res Treat 2017;46:1-6.

22. Manimekaalai P, Dhanalakshmi R, Manavalan R. Preparation and characterization of ceftriaxone sodium encapsulated chitosan nanoparticles. Int J Appl Pharm 2017;6:10-5.

23. Madhuri A, Theng G, Sitaphale R, Biyani K. Evaluation o wound healing activity of polyherbal formulation. Int J Curr Pharma Res 2017;6:12-4.

24. Kareem 0, Nisar N, Tabassum N. Mu-opioid receptor antagonists and their role in the treatment of chronic constipation. J Crit Rev 2017;5:1-6. 